\title{
FitorRemediação de Solos Contaminados com Tebuthiuron UTIlizando-Se Espécies Cultivadas PARA AdUbaÇÃo Verde ${ }^{1}$
}

\author{
Phytoremediation of Tebuthiuron-Contaminated Soils Using Species Cultivated for \\ Green Manure
}

\author{
PIRES, F.R. ${ }^{2}$, SOUZA, C.M. ${ }^{3}$, SILVA, A.A. ${ }^{3}$, CECON, P.R. ${ }^{4}$, PROCÓPIO, S.O. ${ }^{2}$, SANTOS, J.B. ${ }^{5}$ e \\ FERREIRA, L.R. ${ }^{3}$
}

\begin{abstract}
RESUMO - O emprego da fitorremediação na despoluição de solos contaminados com compostos orgânicos, inclusive herbicidas, vem sendo pesquisado ultimamente. Como o tebuthiuron pode causar sério impacto ambiental, por ser muito utilizado, apresentar longo efeito residual no solo e possibilidade de contaminação do lençol de água subterrâneo, desenvolveu-se este trabalho com o objetivo de avaliar a capacidade de sete espécies vegetais na despoluição de solos contaminados com esse herbicida. As espécies avaliadas neste experimento foram: Cajanus cajan, Canavalia ensiformes, Dolichos lablab, Pannisetum glaucum, Estizolobium deeringianum, Estizolobium aterrimum e Lupinus albus. Elas foram semeadas e cultivadas, por 60 dias, em vasos cujo solo recebeu quatro doses do tebuthiuron $(0,0 ; 0,5$; 1,0; e 1,5 $\left.\mathrm{kg} \mathrm{ha}^{-1}\right)$. As testemunhas foram constituídas por vasos sem planta, aos quais foram aplicadas as mesmas doses de herbicidas. Aos 60 dias após a semeadura, colheu-se a parte aérea de todas as plantas, sendo semeada, nos mesmos vasos, Avena strigosa, utilizada como planta indicadora, para realização do bioensaio. Depois de 60 dias da semeadura da espécie bioindicadora, esta foi colhida, sendo avaliadas as seguintes características: altura de plantas, sintomas de toxicidade e biomassa seca da parte aérea das plantas. Até a dose de $0,5 \mathrm{~kg} \mathrm{ha}^{-1}$ de tebuthiuron, a espécie que melhor fitorremediou esse herbicida no solo foi L. albus. Quando o solo foi tratado com $1,0 \mathrm{~kg} \mathrm{ha}^{-1}$ de tebuthiuron, C. ensiformes foi a espécie que melhor fitorremediou o herbicida. Isso foi concluído com base na maior altura de plantas, biomassa seca da parte aérea e menor toxicidade de A. strigosa, quando foi cultivada em sucessão a essas plantas remediadoras. Nenhuma das espécies avaliadas cresceu em solo que recebeu a maior dose de tebuthiuron (1,5 $\left.\mathrm{kg} \mathrm{ha}^{-1}\right)$.
\end{abstract}

Palavras-chave: fitorremediação, despoluição do solo, fitodegradação, bioensaio, aveia-preta.

\begin{abstract}
Phytoremediation of soil contaminated by organic compounds, including herbicides, is being widely investigated. The frequent use of tebuthiuron can cause serious environmental impacts such as long-term residual effect on soil and likely underground water contamination. Thus, this work aimed to evaluate the phytoremediation potential of seven plant species in soils treated with this herbicide. The experiment evaluated the following species: Cajanus cajan, Canavalia ensiformes, Dolichos lablab, Pannisetum glaucum, Estizolobium deeringianum, Estizolobium aterrimum and Lupinus albus, sown and cultivated for 60 days in vases treated with tebuthiuron at $0.0,0.5,1.0$, and $1.5 \mathrm{~kg} \mathrm{ha}^{-1}$. The control treatments were constituted by vases without plants, submitted to the same herbicide doses. Sixty days after sowing, the aerial part of all the plants was harvested and Avena strigosa was sown in the same vases for bioassay. Sixty days after it was sown, A. strigosa was harvested and the characteristics plant height, phytotoxicity symptoms and dry biomass of the aerial part of the plant were evaluated. Up to a tebuthiuron dose of $0.5 \mathrm{~kg} \mathrm{ha}^{-1}, \mathbf{L}$. albus presented the best phytoremediation results. When tebuthiuron was applied at $1.0 \mathrm{~kg} \mathrm{ha}{ }^{-1}$, C. ensiformes presented the best phytoremediation results. Such results were based on plant height, dry biomass of the aerial part
\end{abstract}

Recebido para publicação em 25/11/2004 e na forma revisada em 25/11/2005.

2 Prof. da Faculdade de Agronomia da Universidade de Rio Verde - FESURV, Fazenda Fontes do Saber, Campus Universitário, Caixa Postal 104, 75901-970 Rio Verde-GO, < frpires@ fesurv.br>, <procopio@ fesurv.br>. ${ }^{3}$ Prof. do Dep. de Fitotecnia da Universidade Federal de Viçosa - UFV, 36570-000 Viçosa-MG, <cmsouza@ufv.br>, <aasilva@ ufv.br>; ${ }^{4}$ Prof. do Dep. de Informática - UFV, <cecon@ufv.br>; ${ }^{5}$ Bolsista Pós-Doutor do Dep. de Fitotecnia - UFV, <jbarbosasantos@ yahoo.com.br>. 
and lower A. strigosa phytotoxicity when cultivated after these remediating plants. None of the species evaluated grew in soil receiving the highest dose of tebuthiuron $\left(1.5 \mathrm{~kg} \mathrm{ha} \mathrm{h}^{-1}\right)$.

Key words: phytoremediation, soil depollution, phytodegradation, bioassay, Avena strigosa.

\section{INTRODUÇÃO}

Atualmente, é crescente o interesse pela fitorremediação de solos poluídos. Essa técnica objetiva a descontaminação de solo e água utilizando-se plantas como agente descontaminador (Newman et al., 1998), o que pode ser decorrente da assimilação direta dos contaminantes e subseqüente acumulação de metabólitos não-tóxicos nos tecidos vegetais, como componentes estruturais, e do estímulo da atividade microbiana provocada pela planta, liberando exsudatos que favorecem o aumento da mineralização do contaminante na região da rizosfera (Scramin et al., 2001).

A fitorremediação pode ser usada em áreas contaminadas com substâncias orgânicas e/ou inorgânicas. Resultados promissores de fitorremediação já foram obtidos para metais pesados, metalóides, hidrocarbonetos de petróleo, pesticidas, explosivos, solventes clorados e subprodutos tóxicos da indústria (Cunninghan et al., 1996).

No entanto, solos contaminados com herbicidas apresentam certas limitações à seleção de espécies de plantas fitorremediadoras, quando comparados com outros contaminantes orgânicos ou inorgânicos, por serem, muitas vezes, tóxicos às plantas, principalmente onde estão presentes compostos com largo espectro de ação, como o tebuthiuron (Meyer \& Bovey, 1988; Johnsen \& Morton, 1991). Todavia, alguns trabalhos relatam a contribuição de plantas, estimulando o efeito rizosférico na aceleração da mineralização de alguns herbicidas, principalmente atrazine e metolachlor (Anderson et al., 1994; Anderson \& Coats, 1995; Perkovich et al., 1996; Burken \& Schnoor, 1996) e simazine (Wilson et al., 2000).

No trabalho desenvolvido por Arthur et al. (2000), constatou-se que, nos solos rizosféricos de Kochia scoparia, a meia-vida da atrazine foi de 50 dias, e, nos solos não-vegetados, de 193 dias. Esses resultados demonstram, clara- mente, o potencial da utilização de plantas como remediadoras de pesticidas.

No Brasil, recentes pesquisas têm difundido a utilização de plantas na remediação de herbicidas (Scramin et al., 2001; Pires et al., 2003b; Procópio et al., 2004, 2005; Santos et al., 2004a, b). Desse modo, a aplicação de fitorremediação na despoluição de solos contaminados com o herbicida tebuthiuron, que desperta interesse por apresentar longo efeito residual no solo (Bovey et al., 1982) e elevada solubilidade (Steinert \& Stritzke, 1977), pode representar alternativa vantajosa em situações em que os níveis desse composto sejam elevados no solo e as condições deste favoreçam sua lixiviação.

O tebuthiuron é aplicado no solo, onde é absorvido pelas raízes e acumulado na parte aérea (Steinert \& Stritzke, 1977). Esses autores constataram que a absorção diferenciada apresentada pelas espécies vegetais contribui para a maior ou menor suscetibilidade ao tebuthiuron. Como grande parte desse herbicida absorvido é metabolizada a compostos menos tóxicos na planta (McNeil et al., 1984), aquelas que são tolerantes acumulam mais metabólitos, menos moléculas originais de tebuthiuron e não o acumulam em quantidades fitotóxicas, ao contrário do que ocorre com espécies sensiveis a esse herbicida (Johnsen \& Morton, 1991). Essas informações são importantes para a aplicação da fitodegradação, que é um processo no qual o contaminante é absorvido pela planta e metabolizado na parte aérea (Ferro et al., 1994). Esta forma de tratamento de solos poluídos foi comprovada por Burken \& Schnoor (1996), os quais observaram que cerca de 91\% do atrazine lábil aplicado foi absorvido e assimilado por uma espécie conhecida como Poplar em nove dias, quando cultivada em areia, e 30\% em 80 dias, quando em solo franco-siltoso.

As pesquisas envolvendo a fitorremedia- 
ção de diferentes contaminantes empregam técnicas experimentais que podem ser executadas em laboratório, casa de vegetação e campo. Nos estudos de casa de vegetação, o emprego de plantas indicadoras, sensiveis ao composto avaliado e cultivadas em sucessão, no próprio vaso ou em outros recipientes, fornece informações importantes a respeito do contaminante, norteando pesquisas mais refinadas. Normalmente, estas são corroboradas nas determinações cromatográficas ou cintilação líquida; por outro lado, do ponto de vista fitotécnico, conseguem elucidar diversos questionamentos, que são posteriormente levados a campo. Ensaios biológicos foram empregados no estudo da persistência e da degradação do tebuthiuron (Chang \& Stritzke, 1977; Bovey et al., 1982; Whisenant \& Clary, 1987) e também no estudo da fitorremediação de solos contaminados com óleo diesel (Tesar et al., 2002).

Este trabalho teve como objetivo avaliar a fitorremediação proporcionada por sete espécies de plantas cultivadas para adubação verde, em solos contaminados com tebuthiuron, utilizando aveia-preta como planta indicadora.

\section{MATERIAL E MÉTODOS}

O experimento foi conduzido em casa de vegetação da Universidade Federal de Viçosa. A unidade experimental foi o vaso de polietileno com capacidade para $5 \mathrm{dm}^{3}$ de substrato. Utilizou-se material de solo classificado como Argissolo Vermelho-Amarelo, coletado sob vegetação de mata secundária, na profundidade de $0-20 \mathrm{~cm}$, peneirado em malha de $4 \mathrm{~mm}$ e caracterizado física, química e físico-quimicamente (Tabela 1). Essa caracterização serviu de base para o cálculo das necessidades de correção de pH e de adubação, visando o bom desenvolvimento das espécies avaliadas como fitorremediadoras e da planta indicadora.

O experimento foi montado seguindo esquema fatorial $8 \times 4$ (7 espécies +1 testemunha $=8$ e 4 doses) no delineamento de blocos ao acaso, com três repetições. No ensaio, foram utilizadas sete espécies de adubos verdes, previamente selecionadas quanto à tolerância ao herbicida tebuthiuron: feijãoguandu (Cajanus cajan), feijão-de-porco (Canavalia ensiformis), lablabe (Dolichos lablab), milheto (Pannisetum glaucum), mucuna-anã (Estizolobium deeringianum), mucuna-preta (Estizolobium aterrimum) e tremoço-branco (Lupinus albus), sendo mantidas testemunhas sem planta, submetidas às mesmas condições. O tebuthiuron foi aplicado em pré-emergência, nas doses de 0,$0 ; 0,5 ; 1,0$; e $1,5 \mathrm{~kg} \mathrm{ha}^{-1}$, utilizando-se a marca Combine 500 SC. Na aplicação do herbicida utilizou-se pulverizador de precisão, pressurizado com gás carbônico $\left(\mathrm{CO}_{2}\right)$ e bicos 110.03, trabalhando com pressão de $200 \mathrm{KPa}$ e aplicando-se o equivalente a $260 \mathrm{~L} \mathrm{ha}^{-1}$ de calda.

A semeadura das espécies fitorremediadoras foi realizada um dia após a aplicação do tebuthiuron. Após a semeadura das espécies, os vasos foram irrigados de forma a manter a umidade do solo em torno de $80 \%$ da capacidade de campo, por 60 dias. Após esse período, a parte aérea de todas as plantas foi colhida e o solo foi adubado, sendo imediatamente se-

Tabela 1 - Composição física, química e físico-química do solo utilizado no experimento ${ }^{1}$

\begin{tabular}{|c|c|c|c|c|c|c|c|c|c|c|}
\hline \multicolumn{11}{|c|}{ Análise Granulométrica $\left(\mathrm{dag} \mathrm{kg}^{-1}\right)$} \\
\hline & Argila & \multicolumn{2}{|c|}{ Silte } & \multicolumn{2}{|c|}{ Areia Fina } & \multicolumn{2}{|c|}{ Areia Grossa } & \multicolumn{3}{|c|}{ Classificação Textural } \\
\hline & 47 & \multicolumn{2}{|c|}{8} & \multicolumn{2}{|c|}{14} & \multicolumn{2}{|c|}{31} & \multicolumn{3}{|c|}{ Argilo-arenosa } \\
\hline \multicolumn{11}{|c|}{ Análise Química } \\
\hline $\mathrm{pH}$ & $\mathrm{P}$ & $\mathrm{K}^{+}$ & $\mathrm{Al}^{3+}$ & $\mathrm{Ca}^{2+}$ & $\mathrm{Mg}^{2+}$ & $\mathrm{H}+\mathrm{Al}$ & CTC total & $\mathrm{V}$ & $\mathrm{m}$ & $\mathrm{MO}$ \\
\hline$\left(\mathrm{H}_{2} \mathrm{O}\right)$ & \multicolumn{2}{|c|}{$\left(\mathrm{mg} \mathrm{dm}^{-3}\right)$} & \multicolumn{5}{|c|}{$\left(\mathrm{cmol}_{\mathrm{c}} \mathrm{dm}^{-3}\right)$} & \multicolumn{2}{|c|}{$(\%)$} & $\left(\right.$ dag kg $\left.^{-1}\right)$ \\
\hline 5,6 & 10,6 & 60 & 0,0 & 2,6 & 0,6 & 2,64 & 5,99 & 56 & 0 & 2,39 \\
\hline
\end{tabular}

1/ Análises realizadas nos Laboratórios de Análises Físicas e Químicas de Solo do Departamento de Solos da UFV, segundo a metodologia da Empresa Brasileira de Pesquisa Agropecuária-EMBRAPA (1997). 
meada a aveia-preta (A. strigosa), como planta indicadora no bioensaio, no próprio vaso, e cultivada por mais 60 dias. A aveia-preta foi escolhida como planta indicadora em razão da elevada suscetibilidade que apresenta ao tebuthiuron, conforme verificado em ensaio anterior (Pires et al., 2003a). Ao término desse período, foram avaliados a altura de plantas, a biomassa seca da parte aérea e os sintomas de intoxicação nas plantas de aveia-preta.

Os dados foram submetidos à análise de variância e regressão. As médias do fator qualitativo (espécies remediadoras) foram comparadas, utilizando-se o teste de Duncan a 5\% de probabilidade. Para o fator quantitativo (doses), os modelos foram escolhidos com base no coeficiente de determinação e no fenômeno biológico. Independentemente de a interação ser ou não significativa, optou-se pelo seu desdobramento. Para algumas características avaliadas e espécies, por não atenderem às pressuposições de homogeneidade e normalidade na análise de variância, realizou-se a análise descritiva dos dados.

\section{RESULTADOS E DISCUSSÃO}

Constata-se, avaliando os resultados apresentados nas Figuras 1, 2, 3, 4 e 5 e na Tabela 2, o efeito significativo das doses de tebuthiuron sobre altura, biomassa seca da parte aérea e também sobre a porcentagem de toxicidade desse herbicida na planta indicadora (aveia-preta), quando em sucessão às diferentes espécies fitorremediadoras ou às testemunhas sem planta. A altura das plantas e a biomassa seca da parte aérea da aveiapreta diminuíram com o aumento das doses de tebuthiuron para as sete espécies avaliadas. A fitotoxicidade visual, para todas as espécies avaliadas, aumentou com o incremento da dose do tebuthiuron (Figuras 4 e 5 e Tabela 2).

Para as características altura de plantas e biomassa seca da parte aérea, as espécies fitorremediadoras apresentaram comportamento similar. Quando cultivada em sucessão a praticamente todos os adubos verdes avaliados, a aveia-preta apresentou brusca redução da altura e da biomassa seca a partir da dose de $0,5 \mathrm{~kg} \mathrm{ha}^{-1}$, não se desenvolvendo na dose de $1,5 \mathrm{~kg} \mathrm{ha}^{-1}$, em razão da elevada toxicidade apresentada pelo tebuthiuron (Figura $1 \mathrm{e}$ Tabela 2).

Quando se observam os sintomas de fitotoxicidade, verifica-se aumento em todos os tratamentos com o incremento da dose de tebuthiuron, sendo o feijão-de-porco a espécie que promoveu maior tolerância à aveia-preta cultivada em seqüência. Esta apresentou sintomas agudos de intoxicação apenas a

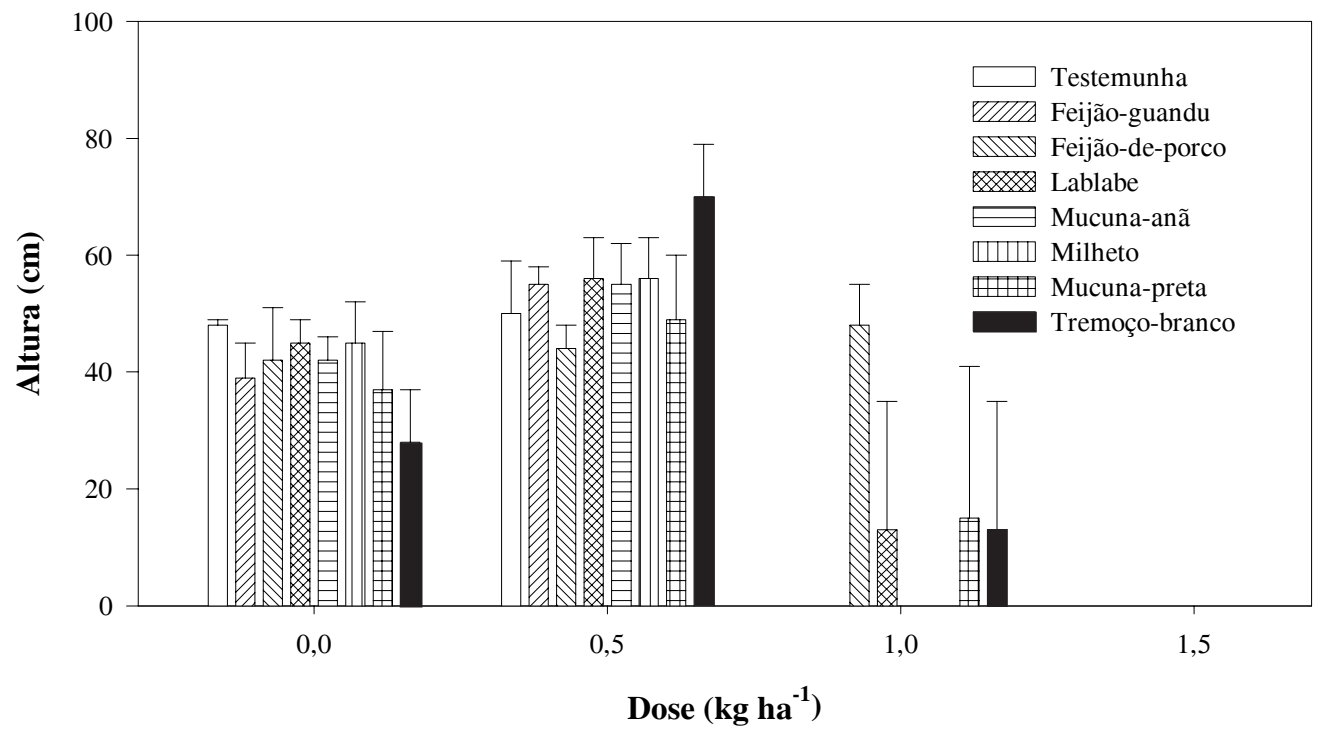

Figura 1 - Altura de plantas de aveia-preta cultivada em sucessão a sete espécies fitorremediadoras e a testemunhas sem planta, em solo tratado com quatro doses de tebuthiuron. 
partir da dose de $1,0 \mathrm{~kg} \mathrm{ha}^{-1}$, atingindo morte completa das plantas na dose de $1,5 \mathrm{~kg} \mathrm{ha}^{-1}$.

Nota-se, nos dados apresentados na Tabela 2, maior altura das plantas de aveia-preta quando cultivadas em sucessão a tremoçobranco, na dose de $0,5 \mathrm{~kg} \mathrm{ha}^{-1}$, não diferindo de feijão-guandu, lablabe, mucuna-anã e milheto. Entretanto, em solo tratado com $1,0 \mathrm{~kg} \mathrm{ha}^{-1}$ de tebuthiuron, o feijão-de-porco foi a espécie que proporcionou maior altura de plantas para a aveia-preta cultivada em seqüência.

Quando se analisa a biomassa seca das plantas de aveia-preta, o comportamento é similar ao observado para altura, com diminuição da fitotoxicidade do tebuthiuron quando feijão-de-porco foi cultivado anteriormente à

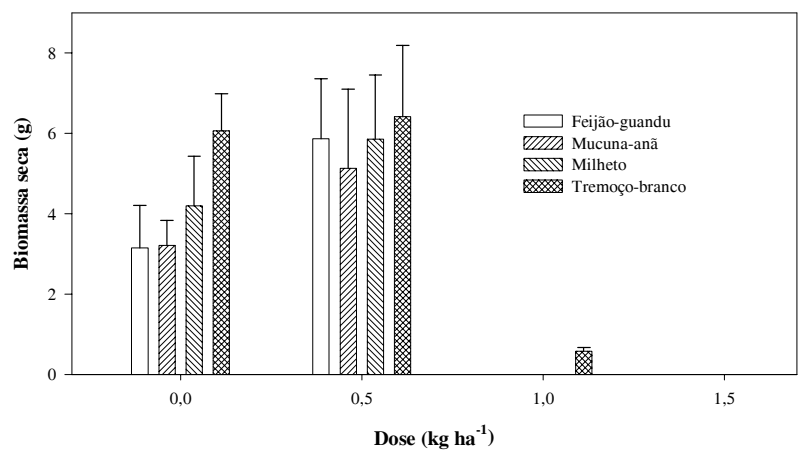

Figura 2 - Biomassa seca de plantas de aveia-preta cultivada em sucessão a feijão-guandu, mucuna-anã, milheto e tremoço-branco, em solo tratado com quatro doses de tebuthiuron.

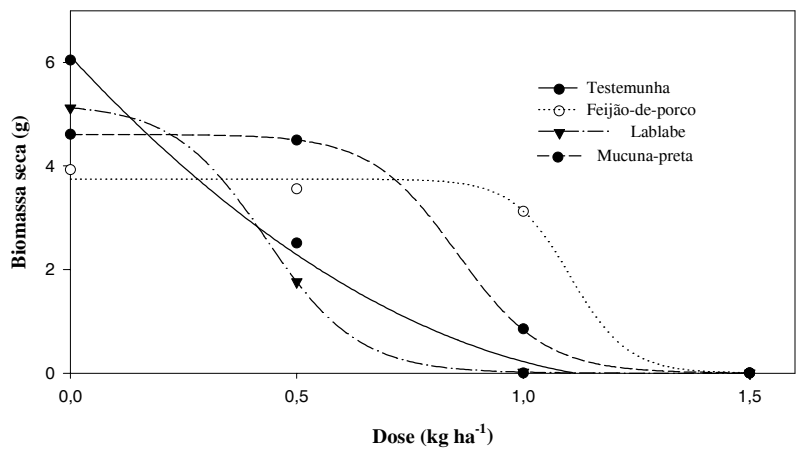

Figura 3 - Biomassa seca de plantas de aveia-preta cultivada em sucessão a feijão-de-porco $[\hat{Y}=3,7452 /(1+\exp (-(D$ $\left.-1,1027) /-0,0639)), \mathrm{R}^{2} 0,99\right]$, lablabe $[\hat{\mathrm{Y}}=5,1954 /$ $\left.(1+\exp (-(\mathrm{D}-0,4316) /-0,1023)), \mathrm{R}^{2} 1,00\right]$, mucuna-preta $\left[\hat{\mathrm{Y}}=4,6103 /(1+\exp (-(\mathrm{D}-0,8550) /-0,0957)), \mathrm{R}^{2} 1,00\right] \mathrm{e}$ testemunhas sem planta $\left(\hat{\mathrm{Y}}=6,1145-9,4210 \mathrm{D}+3,53 \mathrm{D}^{2}\right.$, $\mathrm{R}^{2}$ 0,99), em solo tratado com quatro doses de tebuthiuron. aveia-preta, possibilitando seu desenvolvimento em solo com esse herbicida, com pequena redução de biomassa até a dose de $1,0 \mathrm{~kg} \mathrm{ha}^{-1}$.

Nota-se menor fitotoxicidade do tebuthiuron sobre aveia-preta quando cultivada em seqüência ao milheto, tremoço e feijãoguandu, na dose de $0,5 \mathrm{~kg} \mathrm{ha}^{-1}$. A partir dessa dose, as plantas exibiram severos sintomas de intoxicação, os quais foram menores quando cultivadas em seqüência ao feijão-de-porco.

É interessante notar que seis das sete espécies avaliadas pertencem à família das leguminosas e que, apesar disso, apresentaram desempenho diferenciado quanto à fitorremediação do tebuthiuron. Anderson \& Coats (1995) constataram que a família das plantas não foi um parâmetro adequado

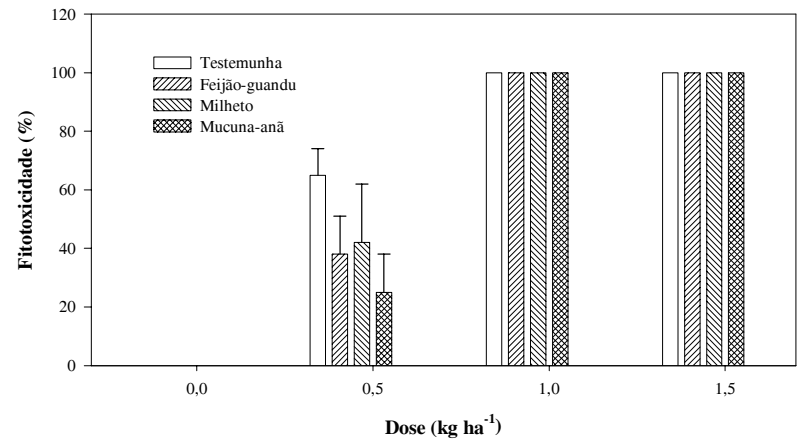

Figura 4 - Toxicidade em plantas de aveia-preta cultivada em sucessão a feijão-guandu, mucuna-anã, milheto e testemunhas sem planta, em solo tratado com quatro doses de tebuthiuron.

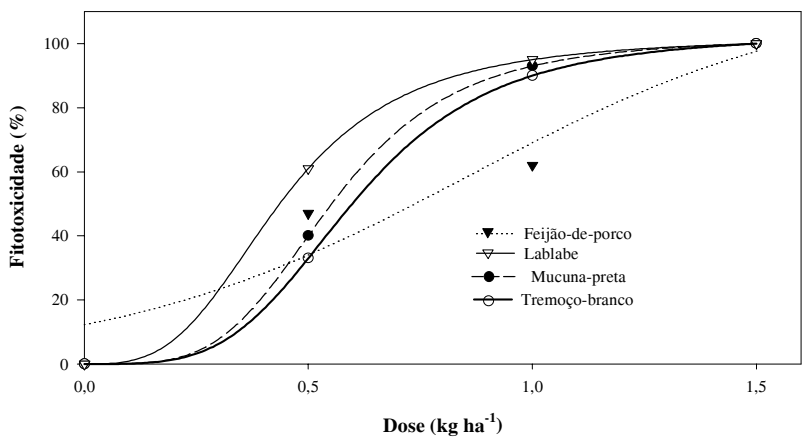

Figura 5 - Toxicidade em plantas de aveia-preta cultivada em sucessão a feijão-de-porco [ŶY $=116,8185 /(1+\exp (-(D$ $\left.-0,8530) /-0,3978)), \mathrm{R}^{2} 0,92\right]$, lablabe [ $\hat{\mathrm{Y}}=102,0384 /(1+(\mathrm{D} /$ $\left.\left.0,4415)^{-3,1828}\right), \mathrm{R}^{2} 1,00\right]$, mucuna-preta $[\hat{\mathrm{Y}}=102,0506 /$ $\left.\left(1+(\mathrm{D} / 0,5590)^{-3,9378}\right) \mathrm{R}^{2} 1,00\right]$ e tremoço-branco $[\hat{\mathrm{Y}}=$ $\left.103,2572 /\left(1+(\mathrm{D} / 0,6079)^{-3,7914}\right), \mathrm{R}^{2} 1,00\right]$, em solo tratado com quatro doses de tebuthiuron.

Planta Daninha, Viçosa-MG, v. 23, n. 4, p. 711-717, 2005 
para prever o aumento da mineralização de atrazine, pois bons resultados foram obtidos com plantas de famílias diferentes, o que concorda com os resultados obtidos neste trabalho.

$\mathrm{Na}$ tentativa de identificar espécies de plantas tolerantes a herbicidas em áreas de cultivo de cana-de-açúcar, no Estado de São Paulo, para utilização em programas de fitorremediação, Scramin et al. (2001) observaram a ocorrência mais freqüente de oito espécies de plantas daninhas persistentes, supostamente tolerantes aos herbicidas mais comumente utilizados nas áreas de cultivo de cana-de-açúcar na região, sendo elas: Cynodon dactylon, Cyperus rotundus, Digitaria

Tabela 2 - Valores médios de altura de plantas, biomassa seca da parte aérea e sintomas de fitotoxicidade de aveia-preta semeada $^{1 /}$ em sucessão a sete espécies fitorremediadoras, em solo tratado com quatro doses de tebuthiuron

\begin{tabular}{|c|c|c|c|c|}
\hline \multirow{3}{*}{ Espécie } & \multicolumn{4}{|c|}{ Dose $\left(\mathrm{kg} \mathrm{ha}^{-1}\right)$} \\
\hline & 0,0 & 0,5 & 1,0 & 1,5 \\
\hline & \multicolumn{4}{|c|}{ Altura $(\mathrm{cm})$} \\
\hline Testemunha & $48,39 \mathrm{~A}^{*}$ & $49,67 \mathrm{~B}$ & $0,00 \mathrm{~B}$ & 0,00 \\
\hline Feijão-guandu & $38,69 \mathrm{AB}$ & $55,22 \mathrm{AB}$ & $0,00 \mathrm{~B}$ & 0,00 \\
\hline Feijão-de-porco & $41,61 \mathrm{AB}$ & $44,33 \mathrm{~B}$ & $47,56 \mathrm{~A}$ & 0,00 \\
\hline Lablabe & $44,89 \mathrm{~A}$ & $56,83 \mathrm{AB}$ & $12,67 \mathrm{~B}$ & 0,00 \\
\hline Mucuna-anã & $41,69 \mathrm{AB}$ & $55,27 \mathrm{AB}$ & $0,00 \mathrm{~B}$ & 0,00 \\
\hline Milheto & $44,56 \mathrm{~A}$ & $55,72 \mathrm{AB}$ & $0,00 \mathrm{~B}$ & 0,00 \\
\hline Mucuna-preta & $37,06 \mathrm{AB}$ & $48,67 \mathrm{~B}$ & $15,00 \mathrm{~B}$ & 0,00 \\
\hline \multirow[t]{2}{*}{ Tremoço-branco } & $27,53 \mathrm{~B}$ & $69,66 \mathrm{~A}$ & $12,67 \mathrm{~B}$ & 0,00 \\
\hline & \multicolumn{4}{|c|}{ Biomassa seca da parte aérea $(\mathrm{g})$} \\
\hline Testemunha & $6,04 \mathrm{~A}$ & $2,51 \mathrm{DE}$ & $0,00 \mathrm{~B}$ & 0,00 \\
\hline Feijão-guandu & $3,15 \mathrm{C}$ & $5,87 \mathrm{AB}$ & $0,00 \mathrm{~B}$ & 0,00 \\
\hline Feijão-de-porco & $3,93 \mathrm{BC}$ & $3,57 \mathrm{CD}$ & $3,12 \mathrm{~A}$ & 0,00 \\
\hline Lablabe & $5,12 \mathrm{AB}$ & $1,76 \mathrm{E}$ & $0,02 \mathrm{~B}$ & 0,00 \\
\hline Mucuna-anã & $3,22 \mathrm{C}$ & $5,13 \mathrm{ABC}$ & $0,00 \mathrm{~B}$ & 0,00 \\
\hline Milheto & $4,20 \mathrm{BC}$ & $5,85 \mathrm{AB}$ & $0,00 \mathrm{~B}$ & 0,00 \\
\hline Mucuna-preta & $4,20 \mathrm{BC}$ & $4,50 \mathrm{BC}$ & $0,83 \mathrm{~B}$ & 0,00 \\
\hline \multirow[t]{2}{*}{ Tremoço-branco } & $6,06 \mathrm{~A}$ & $6,42 \mathrm{~A}$ & $0,58 \mathrm{~B}$ & 0,00 \\
\hline & \multicolumn{4}{|c|}{ Fitotoxicidade $(\%)$} \\
\hline $\begin{array}{l}\text { Testemunha } \\
\text { Testemunuman. }\end{array}$ & 0 & $65 \mathrm{~A}$ & $100 \mathrm{~A}$ & 100 \\
\hline Feijão-guandu & 0 & $38 \mathrm{BC}$ & $100 \mathrm{~A}$ & 100 \\
\hline Feijão-de-porco & 0 & $47 \mathrm{~B}$ & $62 \mathrm{~B}$ & 100 \\
\hline Lablabe & 0 & $61 \mathrm{~A}$ & $95 \mathrm{~A}$ & 100 \\
\hline Mucuna-anã & 0 & $42 \mathrm{~B}$ & $100 \mathrm{~A}$ & 100 \\
\hline Milheto & 0 & $25 \mathrm{C}$ & $100 \mathrm{~A}$ & 100 \\
\hline Mucuna-preta & 0 & $40 \mathrm{~B}$ & $93 \mathrm{~A}$ & 100 \\
\hline Tremoço-branco & 0 & $33 \mathrm{BC}$ & $90 \mathrm{~A}$ & 100 \\
\hline
\end{tabular}

1/ Semeada 60 dias após o tratamento do solo com tebuthiuron.

* Médias seguidas por mesma letra maiúscula, na coluna, dentro de cada característica avaliada, não diferem entre si pelo teste de Duncan a $5 \%$ de probabilidade.

Planta Daninha, Viçosa-MG, v. 23, n. 4, p. 711-717, 2005 horizontalis, Commelina benghalensis, Brachiaria decumbens, Euphorbia heterophylla, Chamaesyce hirta e Chamaesyce hyssopifolia. As espécies encontradas são, notadamente, de difícil controle na maioria das culturas em que ocorrem e apresentam alta capacidade de competição com estas . Assim, sua introdução com o objetivo de fitorremediar o solo poderia representar um problema posterior de infestação da área. Em razão disso, as pesquisas envolvendo espécies de interesse agronômico, como os adubos verdes, são mais indicadas, porque, além de fácil controle, produzem elevada biomassa fresca e seca e, por serem leguminosas, promovem a fixação do nitrogênio atmosférico.

Pode haver a necessidade de mais de um ciclo de cultivo de feijão-de-porco e tremoçobranco, bem como de mucuna-preta e lablabe, para promover significativa redução do tebuthiuron no solo, a fim de permitir, de forma segura, a indicação do cultivo de espécies sensiveis em rotação. Isso foi o que observaram Kruger et al. (1997), em estudo para seleção de espécies capazes de descontaminar solos de quatro locais contaminados com atrazine, em Iowa, EUA. Os autores observaram a possibilidade de se fitorremediar o herbicida atrazine no solo com a espécie $K$. scoparia, porém evidenciaram ser necessário mais de um ciclo de cultivo para eliminação ou redução de atrazine em niveis não-tóxicos no solo.

Até a dose de $1,0 \mathrm{~kg} \mathrm{ha}^{-1}$ de tebuthiuron, a espécie que melhor fitorremediou esse herbicida, com base nos dados de desenvolvimento da aveia-preta, foi o feijão-de-porco, podendo ser indicada para fitorremediação desse herbicida em solo.

\section{AGRADECIMENTOS}

Ao Conselho Nacional de Desenvolvimento Científico e Tecnológico (CNPq), pela concessão da bolsa durante o curso de Doutorado.

\section{LITERATURA CITADA}

ANDERSON, T. A.; COATS, J. R. Screening rhizosphere soil samples for the ability to mineralize elevated concentrations of atrazine and metolachlor. J. Environ. Sci. Health B., v. 30, p. 473-484, 1995. 
ANDERSON, T. A.; KRUGER, E. L.; COATS, J. R. Enhanced degradation of a mixture of three herbicides in the rhizosphere of a herbicide-tolerant plant. Chemosphere, v. 28, p. 1551-1557, 1994.

ARTHUR, E. L. et al. Degradation of an atrazine and metolachlor herbicide mixture in pesticide-contaminated soils from two agrochemical dealerships in Iowa. Water, Air, Soil Poll., v. 119, p. 75-90, 2000.

BOVEY, R. W.; MEYER, R. E.; HEIN JR., H. Soil persistence of tebuthiuron in the Claypan Resource Area os Texas. Weed Sci., v. 30, p. 140-144, 1982.

BURKEN, J. G.; SCHNOOR, J. L. Phytoremediation: plant uptake of atrazine and role of root exudates. J. Environ. Eng., v. 122, p. 958-963, 1996.

CHANG, S. S.; STRITZKE, J. F. Sorption, movement, and dissipation of tebuthiuron in soils. Weed Sci., v. 25, p. 184187, 1977.

CUNNINGHAM, S. D.; ANDERSON, T. A.; SCHWAB, A. P. Phytoremediation of soils contaminated with organic pollutants. Adv. Agron., v. 56, p. 55-114, 1996.

\section{EMPRESA BRASILEIRA DE PESQUISA} AGROPECUÁRIA - EMBRAPA. Manual de métodos de análise de solo. 2.ed. Rio de Janeiro: Centro Nacional de Pesquisa de Solos, 1997. 212 p.

FERRO, A. M.; SIMS, R. C.; BUGBEE, B. Hycrest crested wheatgrass accelerates the degradation of pentachlorophenol in soil. J. Environ. Qual., v. 23, p. 272-279, 1994.

JOHNSEN, T. N.; MORTON, H. L. Long-term tebuthiuron content of grasses and shrubs on semiarid rangelands. J. Range Manag., v. 44, p. 249-253, 1991.

KRUGER, E. L. et al. Atrazine degradation in pesticidecontaminated soils: phytoremediation potential. In: KRUGER, E. L.; ANDERSON, T. A.; COATS, J. R. (Eds.). Phytoremediation of soil and water contaminants. Washington, DC: American Chemical Society, 1997. p. 54-64. (ACS Symposium Series).

McNEIL, W. K.; STRITZKE, F.; BASLER, E. Adsorption, translocation, and degradation of tebuthiuron and hexazinone in woody species. Weed Sci., v. 32, p. 739-743, 1984.

MEYER, R. E.; BOVEY, R. W. Tebuthiuron formulation and placement effects on response of woody plants and soil residue. Weed Sci., v. 36, p. 373-378, 1988.

NEWMAN, L. A. et al. Phytoremediation of organic contaminants: a review of phytoremediation research at the university of Washington. J. Soil Contamin., v. 7, p. 531-542, 1998.
PERKOVICH, B. S. et al. Enhanced mineralization of $\left[{ }^{14} \mathrm{C}\right]$ atrazine in Kochia scoparia rhizosferic soil from a pesticide-contaminated site. Pestic. Sci., v. 46, p. 391-396, 1996.

PIRES, F. R. et al. Seleção de plantas tolerantes ao tebuthiuron e com potencial para fitorremediação. R. Ceres, v. 20, p. 583-594, 2003a.

PIRES, F. R. et al. Fitorremediação de solos contaminados com herbicidas. Planta Daninha, v. 21, p. 335-341, 2003b.

PROCÓPIO, S. O. et al. Potencial de espécies vegetais para a remediação do herbicida trifloxysulfuron-sodium. Planta Daninha, v. 23, n. 1, p. 9-16, 2005.

PROCÓPIO, S. O. et al. Seleção de plantas com potencial para fitorremediação de solos contaminados com herbicida trifloxysulfuron-sodium. Planta Daninha, v. 22, n 2, p. 315-322, 2004.

SANTOS, J. B. et al. Fitorremediação do herbicida trifloxysulfuron sodium. Planta Daninha, v. 22, n. 2, p. 323-330, 2004a.

SANTOS, J. B. et al. Seletividade do herbicida trifloxysulfuron sodium para fins de fitorremediação. R. Ceres, v. 21, n. 293, p. 129-141, 2004b.

SCRAMIN, S.; SKORUPA, L. A.; MELO, I. S. Utilização de plantas na remediação de solos contaminados por herbicidas - levantamento da flora existente em áreas de cultivo de cana-de-açúcar. In: MELO, J. S. et al. (Ed.) Biodegradação. Jaguariúna: Embrapa Meio Ambiente, 2001. p. $369-371$.

STEINERT; W. G.; STRITZKE, J. F. Uptake and phytotoxicity of tebuthiuron. Weed Sci., v. 25, p. 390-395, 1977.

TESAR, M.; REICHENAUER, G.; SESSITSCH, A. Bacterial rhizosphere populations of black poplar and herbal plants to be used for phytoremediation of diesel fuel. Soil Biol. Biochem., v. 34, p. 1883-1892, 2002.

WHISENANT, S. G.; CLARY, W. P. Tebuthiuron distribution in soil following application of pellets. J. Environ. Qual., v. 16, p. 397-402, 1987.

WILSON, P. C.; WHITWELL, T.; KLAINE, S. J. Phytotoxicity, uptake, and distribution of ${ }^{14} \mathrm{C}$-simazine in Acorus gramenius and Pontederia cordata. Weed Sci., v. 48, p. 701-709, 2000. 